\title{
THERMAL PERFORMANCE EVALUATION OF ROOM AIR CONDITIONERS EVAPORATORS
}

\author{
A. C. Piske, \\ L. M. Moura, \\ and N. Mendes \\ Pontifical Catholic University of Paraná \\ 1155, Imaculada Conceicao St \\ 80215-901, Curitiba, Paraná, Brasil \\ alex.piske@petrobras.com.br \\ ABSTRACT \\ This work presents a thermal performance evaluation of a fin-and-tube evaporator - that is \\ widely used in packaged air conditioning equipment - using a balanced calorimeter \\ developed to simulate similar running conditions. The calorimeter determines the heat \\ rate absorbed by the evaporator, providing qualitative analysis of performance for a given \\ geometry. The calorimeter inside air is dried out due to the condensation process on the \\ evaporator under test during the transient period. By this way it is possible to preview the \\ humidity of the calorimeter domain and its influence with the instrumentation measurement. \\ The heat transfer rate absorbed by the evaporator is obtained by a lumped approach using \\ the energy conservation that is applied to the calorimeter domain, and is taken on the \\ boundaries of the equipment. Physical parameters such as overall heat transfer coefficient \\ for several types of fins can then be predicted in order to provide information for improving \\ luis.moura@pucpr.br \\ the energy-efficiency-oriented design. The uncertainties are estimated by the propagation \\ of relative effects. Uncertainties are evaluated taking into account the systematic effects. \\ Results are shown in terms of evaporator overall heat transfer coefficient and heat transfer \\ nathan.mendes@pucpr.br \\ rate as a function of inlet air temperature. \\ Keywords: calorimeter, fin-and-tube evaporator, packaged air conditioner
}

\section{NOMENCLATURE}

$\dot{Q}_{\text {evap }} \quad$ heat transfer rate at the evaporator under test, W

$\dot{Q}_{U A} \quad$ overall heat transfer rate associated to conduction loads through the calorimeter walls, W

$\dot{Q}_{\text {heater }}$ Heater power, W

$\dot{Q}_{\text {vent }} \quad$ dissipated power by fan, W

$n \quad$ number of external surfaces of calorimeter data acquisition point

$T_{\text {VIC }} \quad$ temperature adjusted by the regression

$T_{\mathrm{VI}} \quad$ temperature measured by data acquisition system

U overall heat transfer coefficient

\section{Greek Symbols}

$\beta_{1} \quad$ modulus of a linear curve

$\beta_{0} \quad$ linear parameter of a linear curve

' $T_{c a l}$ temperature difference between wall surfaces of calorimeter, ${ }^{\circ} \mathrm{C}$

\section{INTRODUCTION}

Several studies have focused on the improvement of energy efficiency of room air conditioners over the last three decades, showing that a well-designed evaporator can significantly reduce the energy consumption of those equipments. For instance, geometry-related evaporators parameters play an important role on heat transfer and energy efficiency ratio of air conditioners using standard refrigerating cycles.

Some authors have conducted many research projects on the development of calorimeters for evaluating the thermal performance of evaporators. However, none of them presented evaporator capacity uncertainties of their calorimeter tests. Basically, there are calorimeters that run under either closed-loop or open-loop circuit. For the first type, Liang et al. (2001) developed one closed-loop system, which envelope was not adiabatic. Similarly, Wang et al. (2000) proposed a calorimeter with a well-insulated envelope.

On the other hand, Lee et al. (2002) developed a calorimeter, which inlet psychrometric conditions are kept constant, but condensation of moist air on evaporator surface was disregarded.

Horuz et al. (1998) proposed an open-loop system that dissipates energy at inlet and outlet of the evaporator, improving the calorimeter usability.

In order to improve the evaporators performance accuracy and test flexibility at low costs, Piske et al. (2004) developed a closed-loop 


\section{CIÊNCIA/SCIENCE}

and well-insulated balanced calorimeter equipped with an energy compensation system.

\section{THE CALORIMETER APPARATUS}

The calorimeter (Piske, 2004) is a box, which envelope is thermally insulated with expanded polyurethane, as shown in Fig. 1. The calorimeter inside air is dried out due to the condensation process on the evaporator under test during the transient period. The inside airflow is powered by a fan located at the calorimeter bottom surface. In order to assure the thermal control, an electrical heater is driven by a closed-loop control, which plays a fundamental role assuring temperature stability. The control is done by the data acquisition system, using T-type thermocouples, defining if the relay commutes switching the on/off heater.

Assuring the repeatability of evaporators performance testes results, the calorimeter is connected to a R-134a refrigerating system which feeds continuously the evaporator under test. Then, when the hygrothermal domain of the calorimeter reaches steady-state conditions, it means the heat transfer rate at the evaporator surface is the sum of the heat dissipated by the heater, the heat dissipated by the fan, and the conduction heat transfer rate through the calorimeter envelope. The thermostatic expansion valve adjusts the evaporation temperature assuring no liquid goes to the compressor inlet.

A central system is responsible for the acquisition of electrical measurements taken at fan and heater in order to evaluate their thermal dissipation.

The calorimeter system is placed within a climatic chamber, which assures constant temperatures at the external envelope surfaces. The external temperatures are controlled by recirculating air.

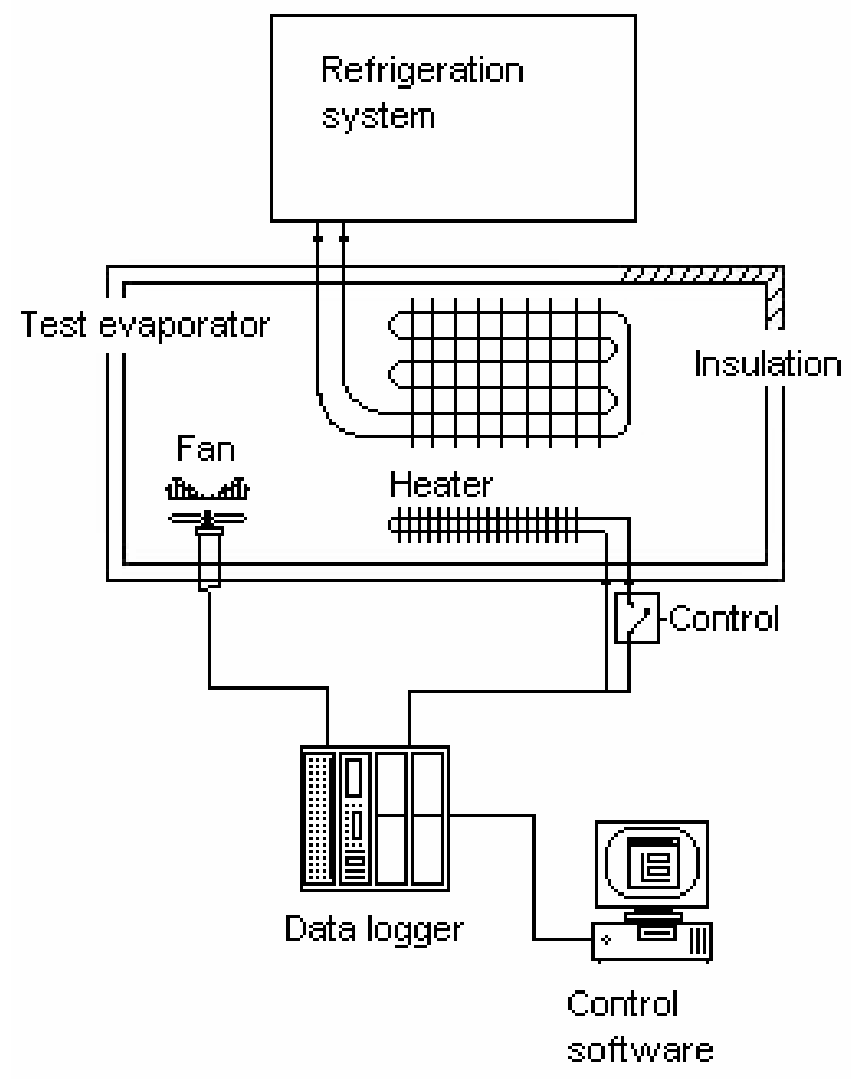

Figure 1. Wired diagram for calorimeter apparatus used for tests.

The heat transfer rate absorbed by the evaporator is obtained by a lumped approach using the energy conservation equation that is applied to the calorimeter domain, which gives:

$$
\dot{Q}_{\text {evap }} \quad \dot{Q}_{U A} \square \dot{Q}_{\text {heater }} \square \dot{Q}_{\text {vent }}
$$

On the other hand, the overall heat transfer rate through the calorimeter envelope may be predicted by a previous test, which is carried out by turning on only the ventilation system, which energy balance results on:

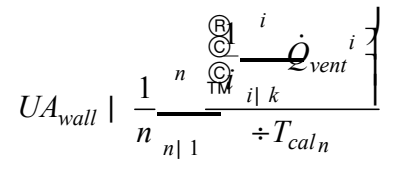

\section{Assessment of overall heat transfer coeffIcient of the CALORIMETER boundaries}

The procedure consists on establishing known heat transfer rate dissipation under similar convection heat transfer conditions when the calorimeter runs, and it is provided by the fan power dissipation, only. On the other hand, the external temperature (chamber temperature) is also 
controlled. Hence, the thermal equilibrium is steadily reached. The energy goes through out an equivalent resistance in that case and is in general composed by three parts two of them due convection inside and outside of calorimeter and the last due to conduction. Its insulation is fulfilled by expanded polyurethane that presents conductivity much lower than offered by convection resistance.

Therefore, the overall heat transfer coefficient of the calorimeter boundaries is done by Eq. (3).

$$
U A_{\text {wall }} \frac{\dot{Q}_{\text {Fan }}}{\overline{\text { Tint } \square \bar{T} \text { ext }}}
$$

The procedure described above is carried out for some different testing temperatures.

Several tests were carried out and compiled, writing UA as a linear regression, Eq. (4).

$$
U A_{\text {wall }} \quad 0.0672^{\prime} T_{\text {int,ext }} \square 4.4872
$$

So, all terms were defined allowing the use of Eq. (1) in the determination of the heat transfer rate of the test evaporator.

\section{MEASUREMENT UNCERTAINTIES}

Uncertainties are estimated by an error propagation method, according to Taylor (1988). The derivation for uncertainties is based on the theory of systematic errors. Beck and Arnold (1977) showed that a systematic error could be arranged as a linear regression.

\section{Uncertainty for Temperature}

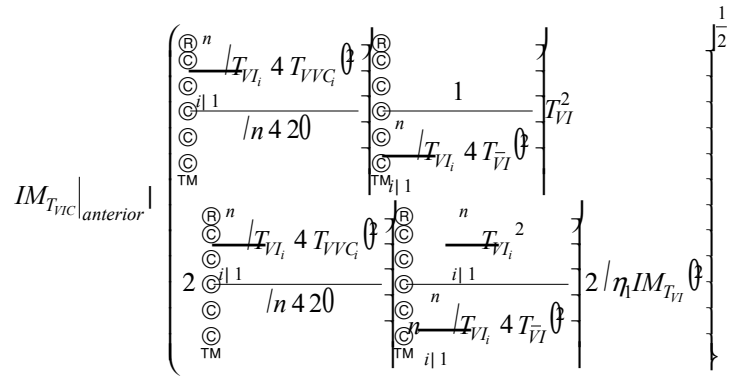

\section{Uncertainty for the Envelope Heat Transfer Coefficient}

The envelope overall heat transfer coefficient, UA, may be written as:
Piske et al. Thermal Performance Evaluation of...

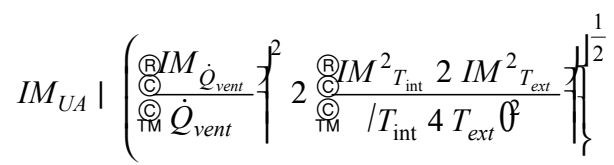

\section{Uncertainty for the Envelope Heat Transfer Rate}

The envelope heat transfer rate uncertainties due to the conduction loads can be evaluated by the following expression:

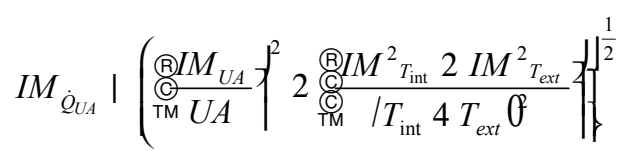

\section{Uncertainty for Evaporator Heat Transfer Rate}

The uncertainty associated to the prediction of heat transfer rate at the evaporator surface can be calculated by:

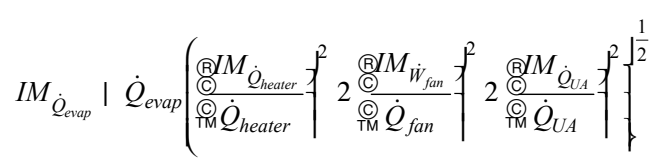

\section{RESULTS}

Table 1 shows the geometric parameters for the two evaporators tested. Tables 2 and 3 present the average data reached by several tests performed with the calorimeter apparatus illustrated in Fig. 1, for different test temperatures.

Table 1. Geometric parameters of evaporators type 1 and 2 .

\begin{tabular}{|c|c|c|}
\hline Type & 1 & 2 \\
\hline Tube length $[\mathrm{m}]$ & 6.420 & 6.667 \\
\hline Diameter $[\mathrm{mm}]$ & 6.7 & 7.5 \\
\hline $\begin{array}{c}\text { Number of fins } \\
\text { (dimension in } \mathrm{mm})\end{array}$ & 156 & 154 \\
\hline Fins density & 0.57 & $(280 \times 44.3)$ \\
\hline Surface $\left[\mathrm{m}^{2}\right]$ & 3.739 & 0.55 \\
\hline
\end{tabular}

Table 2. Average data for evaporator type 1.

\begin{tabular}{|c|c|c|c|}
\hline $\begin{array}{c}\text { Inlet air } \\
\text { temperature } \\
\left({ }^{\circ} \mathrm{C}\right)\end{array}$ & $\begin{array}{c}\text { Evaporation } \\
\text { temperature } \\
\left({ }^{\circ} \mathrm{C}\right)\end{array}$ & $\begin{array}{c}\text { Refrigerant } \\
\text { superheating } \\
\text { degree }\left({ }^{\circ} \mathrm{C}\right)\end{array}$ & $\begin{array}{c}\text { Evaporator } \\
\text { heat rate } \\
(\mathrm{W})\end{array}$ \\
\hline $\mathrm{IM} \leq 0.3$ & $\mathrm{IM} \leq 0.3$ & $\mathrm{IM} \leq 0.3$ & $\mathrm{IM} \leq 0.3$ \\
\hline 31.6 & 24.7 & 0.7 & 488.8 \\
\hline 27.8 & 21.0 & 1.4 & 435.5 \\
\hline 24.0 & 16.9 & 3.5 & 399.2 \\
\hline 20.3 & 10.6 & 6.5 & 359.3 \\
\hline 16.5 & 0.8 & 13.3 & 307.8 \\
\hline 10.6 & -12.6 & 20.9 & 253.6 \\
\hline 6.8 & -11.0 & 15.0 & 217.6 \\
\hline
\end{tabular}


Table 3. Average data for evaporator type 2.

\begin{tabular}{|c|c|c|c|}
\hline $\begin{array}{c}\text { Inlet air } \\
\text { temperature } \\
\left({ }^{\circ} \mathrm{C}\right)\end{array}$ & $\begin{array}{c}\text { Evaporation } \\
\text { temperature } \\
\left({ }^{\circ} \mathrm{C}\right)\end{array}$ & $\begin{array}{c}\text { Refrigerant } \\
\text { superheating } \\
\text { degree }\left({ }^{\circ} \mathrm{C}\right)\end{array}$ & $\begin{array}{c}\text { Evaporator } \\
\text { heat rate } \\
(\mathrm{W})\end{array}$ \\
\hline $\mathrm{IM} \leq 0.3$ & $\mathrm{IM} \leq 0.3$ & $\mathrm{IM} \leq 0.3$ & $\mathrm{IM} \leq 0.3$ \\
\hline 32.5 & 23.0 & 4.9 & 234.0 \\
\hline 31.5 & 26.4 & 1.7 & 298.3 \\
\hline 30.5 & 25.5 & 0.7 & 299.3 \\
\hline 28.7 & 23.5 & 0.9 & 313 \\
\hline 28.3 & 22.8 & 1.5 & 310.9 \\
\hline 23.9 & 17.8 & 2.0 & 374.2 \\
\hline 20.2 & 15.3 & 1.2 & 399.1 \\
\hline 16.4 & 12.7 & 0.3 & 303.1 \\
\hline 10.8 & 7.7 & 1.4 & 203.9 \\
\hline 6.02 & 1.0 & 1.3 & 179.3 \\
\hline
\end{tabular}

In Fig. 2, one can notice that evaporator sample 1 presented better performance than sample 2 for a temperature range between $11^{\circ} \mathrm{C}$ and $28^{\circ} \mathrm{C}$, especially for inlet air temperatures higher than $20^{\circ} \mathrm{C}$ when the evaporation temperature for type 1 is much lower than the one for type 2 .

The evaporator thermal performance can be described by a mathematical expression that takes into account the evaporator heat transfer rate and the temperature difference between the evaporator air inlet and the evaporator refrigerant outlet. This relationship can be viewed in Fig. 3.

Figures 3 and 4 show the same measurements data presented in Fig. 2. However, in Fig. 3, the ratio between the evaporator heat transfer rate and temperature difference between the evaporator air inlet and the evaporator refrigerant outlet is plotted as a function of inlet air temperature.

In Fig. 4, the heat transfer rate is presented as a function of the difference between inlet air temperature and evaporation temperature.

A possible reason for the different behavior noted for the sample-2 evaporator is due to measurement errors on the evaporation temperature.

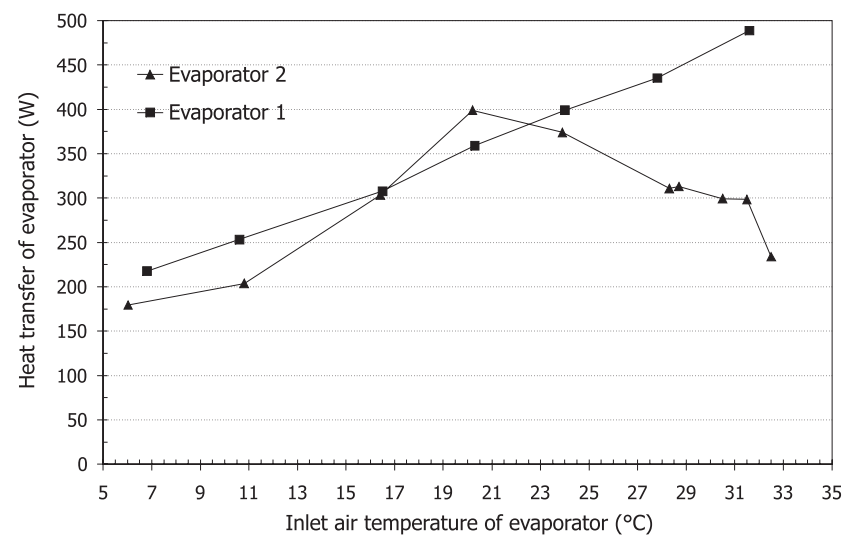

Figure 2. Heat transfer rate comparisons between two distinct fin-and-tube evaporators as a function of inlet air temperature at the evaporator.

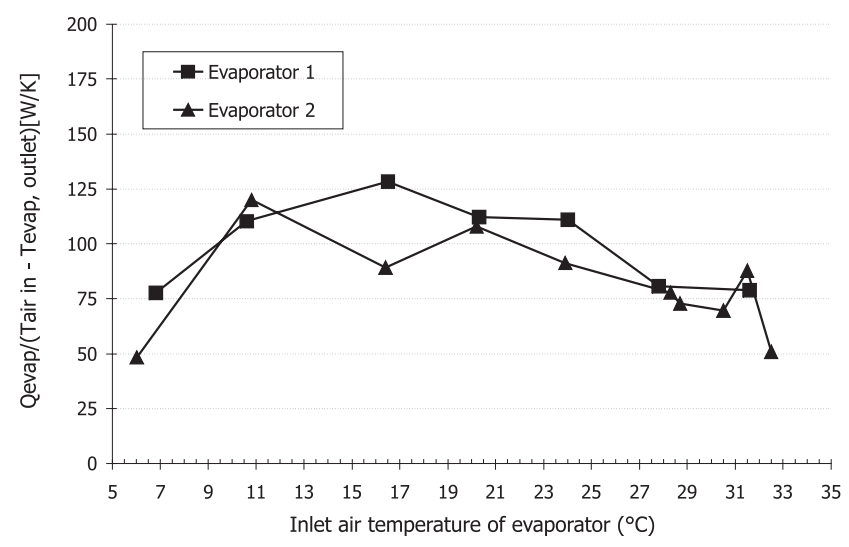

Figure 3. Ratio between heat transfer rate and difference between inlet air temperature and evaporation temperature as a function of inlet air temperature at the evaporator.

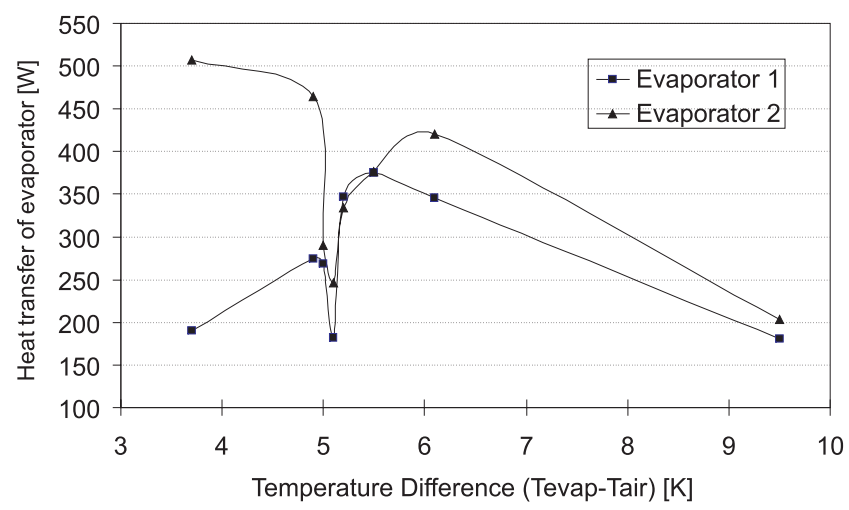

Figure 4. Heat transfer rate comparisons between two distinct fin-and-tube evaporators as a function of the difference between inlet air temperature and evaporation temperature. 


\section{CIÊNCIA/SCIENCE}

\section{CONCLUSIONS}

A calorimeter apparatus and its uncertainties have been presented in this paper. According to the results, one may conclude that the thermal performance evaluation of evaporators using balanced calorimeters is a simple and fastexecuting way to obtain their refrigeration capacity under thermodynamics conditions of moist air that are similar to those found in the field.

Nevertheless, further research should be conducted in order to improve even more the accuracy of results obtained using the calorimeter.

\section{ACKNOWLEDGEMENTS}

The authors thank the research council of the Secretary for Science and Technology of Brazil (CNPq-Energia, Ref. 550093/01-0) for the scholarship to our students at the Thermal Systems Laboratory of the Pontifical Catholic University of Paraná (PUCPR) and Electrolux of Brazil S.A. for their support.

\section{REFERENCES}

Beck, J. V., Arnold, K. J, 1977, Parameter Estimation in Engineering and Science, J. Wiley \& Sons, NY, pp. 130-145.

Horuz, L., Kurem, E., Yamankaradeniz, R., 1998, Experimental and Theoretical Performance Analysis of Air-cooled Plate-finned-tube Evaporators, Int. C. in Heat and Mass Transfer, Vol. 25, No. 6, pp. 787-798.

Liang, S. Y., Wong, T. N., Nathan, G K., 2001, Numerical and Experimental Studies of Refrigeration Circuitry of Evaporators Coils, International Journal of Refrigeration, Vol. 24, pp. 823-833.

Lee, J. H., Bae, S. W., Bang, K. H., Kim, M. H., 2002, Experimental and Numerical Research on Condenser Performance for R-22 and R-407 Refrigerants, International Journal of Refrigeration, Vol. 25, pp. 372-382.

Piske, A. C, 2004, Desenvolvimento de Calorímetro para a Avaliação de Evaporadores, PUCPR, Masters Dissertation, Brazil, 168p.

Piske, A. C., Moura L. M., Mendes N., 2004, Development of a Calorimeter for Evaluating Thermal Performance of Evaporators, 7th Biennial ASME Conference: Engineering Systems Design and Analysis, Manchester, UK, 8 p.
Piske et al. Thermal Performance Evaluation of...

Taylor, J. L., 1988, Fundamentals of Measurement Error, Neff Instrument Co., Monrovia, pp. 74-84.

Wang, C., Lin, Y., Lee, C., 2000, Heat and Momentum Transfer for Compact Louvered Finand-tube-Heat Exchangers in Wet Conditions, Heat and Mass Transfer, Vol. 43, pp. 3443-3452. 